\title{
Epigallocatechin gallate inhibits hepatitis B virus infection in human liver chimeric mice
}

\author{
Yu-Heng Lai ${ }^{1}$, Cheng-Pu Sun ${ }^{2}$, Hsiu-Chen Huang ${ }^{3}$, Jui-Chieh Chen ${ }^{4}$, Hui-Kang Liu ${ }^{5,6}$ and Cheng Huang ${ }^{7,8^{*}}$ (D)
}

\begin{abstract}
Background: Persistent hepatitis B virus (HBV) infection causes liver cirrhosis and hepatocellular carcinoma and constitutes a major worldwide health problem. Currently, anti-HBV drugs are limited to peginterferon and nucleos(t)ide analogs, which are costly and have considerable side effects; the development of novel, effective anti-HBV agents is crucial.

Methods: Catechins are a major group of compounds found in green tea extract and epigallocatechin gallate (EGCG) has been shown to have antiviral properties, including inhibition of cellular entry by HBV. FRG $\left(\mathrm{Fah}^{-/-} / \mathrm{Rag}^{-/-} / \mathrm{IL}-2 \mathrm{R} \gamma^{/-}\right)$mice were used in this study to generate chimeras carrying human primary hepatocytes, to facilitate investigation of the inhibitory effect of EGCG on HBV infection.

Results: Here, we show the inhibitory effect of EGCG on HBV infection and replication in HuS-E/2 cells. The inhibitory effect of EGCG on HBV infection in vivo was confirmed by monitoring HBV DNA and HBsAg in serum and immunostaining the liver tissues of the human liver chimeric mice.

Conclusions: The effects of EGCG suggest a robust strategy for the treatment of HBV infection and EGCG may have therapeutic potential for the treatment of HBV-associated liver diseases.
\end{abstract}

Keywords: Hepatitis B virus, EGCG, HBsAg, Human liver chimeric mice

\section{Background}

Hepatitis B virus (HBV) infection is a major cause of acute and chronic viral hepatitis in humans, with the risk of development of cirrhosis and hepatocellular carcinoma (HCC) [1]. Today, approximately 350 million individuals are chronically infected, despite of the availability of an effective vaccine for more than 25 years [2]. There is an approximately 100 -fold greater relative risk of HCC among HBV carriers than non-carriers [2]. However, many HBV-infected patients have not been treated with antiviral drugs, including interferon-alpha and nucleotide analogues that inhibit the viral reverse transcriptase, because of the adverse side effects and

\footnotetext{
* Correspondence: chengh@ym.edu.tw

7Department of Biotechnology and Laboratory Science in Medicine, National Yang-Ming University, No. 155, Sec. 2, Linong St., Beitou District, Taipei 11221, Taiwan

${ }^{8}$ Department of Earth and Life Sciences, University of Taipei, Taipei 11153, Taiwan

Full list of author information is available at the end of the article
}

development of drug resistance, as well as the high cost of treatment [3]. Therefore, it is crucial to develop safe and effective, as well as affordable, anti-HBV agents that inhibit viral replication and improve the clinical outcome of HBV patients.

HBV is a small DNA virus with a nucleocapsid that protects the $3.2 \mathrm{~kb}$ genome [4]. The nucleocapsid is surrounded by an envelope, which contains three types of hepatitis B surface antigen ( $\mathrm{HBsAg}$ ), the small (S), medium (M) and large (L) forms, with distinct functions [5]. These proteins are encoded by one open reading frame, with three in-phase start codons. The $\mathrm{M}$ form of HBsAg (MHBsAg) has a hydrophilic, 55 amino acids (a) N-terminal extension of the $\mathrm{S}$ domain, known as the pre-S2 domain [6]. The L form of HBsAg (LHBsAg) contains the pre-S1 domain, which extends from the pre-S2 domain for another 108 or 119 aa, dependent on the genotype [6]. The LHBsAg protein plays pivotal roles in the viral entry process $[7,8]$ and, recently, sodium 
taurocholate cotransporting polypeptide (NTCP) was identified as an HBV receptor [9, 10]. Viral entry begins with binding of the externally exposed region of LHBsAg to NTCP [11] . Entry of HBV into uninfected hepatocytes has long been proposed as a potential target for antiviral intervention [12].

In a previous study, we used immortalized human primary hepatocytes, $\mathrm{HuS}-\mathrm{E} / 2$ cells, as a model to screen for natural, bioactive compounds against $\mathrm{HBV}$ infection [13]. We also found that epigallocatechin gallate (EGCG), a flavonoid that belongs to the subclass of catechins and is present in green tea extract, has antiviral and anti-oncogenic properties [14-16] and is able to inhibit HBV entry and contribute to decreased HBV replication in vitro [17]. In this study, we show that EGCG represses the infection of $\mathrm{HBV}$ in $\mathrm{HuS}-\mathrm{E} / 2$ cells.

Fumacrylacetoacetate (Fah) is an enzyme involved in tyrosine metabolism. Fah-deficient mice develop hypoglycemia and liver dysfunction due to the toxicity of accumulated metabolites [18]. In addition, along with the recombination-activating gene2 and IL-2 receptor knock-out (KO) mice that have disrupted immune development, triple $\mathrm{KO}$ mice were generated to engraft human cells in a chimeric model. Previously, FRG (Fah ${ }^{-/-} / \mathrm{Rag}^{-/-} / \mathrm{IL}-2 \mathrm{R} \gamma^{/-}$) mice have been used to generate chimeras carrying human primary hepatocytes. The FRG mouse is well-established and has been used for research into viral liver-associated diseases, providing a solid platform for human hepatic xenorepopulation $[19,20]$. These robust primary hepatocytes have replaced the traditional immortal hepatoma cells or hepatoblasts as a research model, with their viability and differentiation status [20]. Therefore, the human chimeric mouse model of HBV infection is crucial for analyzing EGCG dosage and the timing of treatment. To sum up, our study shows potential to predict prognosis in the clinical setting and the accessibility of the therapeutic effects of EGCG in human patients. This suggests a robust strategy for therapeutic intervention in HBV infection in order to treat the associated liver diseases.

\section{Methods}

\section{Cell culture}

HuS-E/2 [21], and HepG2.2.15 cells (RRID:CVCL_L855), which stably express the HBV genome, were maintained in Dulbecco's modified Eagle's medium supplemented with $10 \%$ heat-inactivated fetal calf serum and $100 \mathrm{U} / \mathrm{ml}$ of penicillin and $100 \mu \mathrm{g} / \mathrm{ml}$ of streptomycin (Gibco). Both HuS-E/2 and HepG2.2.15 cells were cultured at $37{ }^{\circ} \mathrm{C}$ in the presence of $5 \% \mathrm{CO} 2$.

For $\mathrm{HBV}$ infection, $\mathrm{HuS}-\mathrm{E} / 2$ cells were differentiated by incubation with $2 \%$ DMSO for 10 days, as described previously [13].

\section{HBV infection of cell cultures}

$\mathrm{HBV}$ infection experiments were performed as described previously [13]. Briefly, HBV particles were isolated and concentrated from HepG2.2.15 cells. Differentiated $\mathrm{HuS}-\mathrm{E} / 2$ cells were incubated for $20 \mathrm{~h}$ with purified $\mathrm{HBV}$ at a multiplicity of infection (MOI) of 10, in the presence of 0,10 , or $20 \mu \mathrm{M}$ EGCG or DMSO as control, then the HBV and EGCG were removed and the culture medium was changed every 3 days for 7 days.

\section{DNA and RNA isolation, reverse transcription and real- time PCR}

Total DNA was extracted with a Genomic DNA isolation kit (Nexttec Biotechnologie, Germany). Total RNA was isolated from cultured cells using TRIzol $^{\circledR}$ reagent (Invitrogen). Reverse transcription was performed with the RNA templates, AMV reverse transcriptase (Roche), and oligo-dT primer. The products were subjected to real-time PCR with primer sets of specific genes and SYBR Green PCR Master Mix (Bio-Rad). The primer sets used for HBV core, HBsAg, cccDNA and GAPDH were described previously [13]. The results were analyzed with the iCycler $\mathrm{iQ}$ real-time PCR detection system (Bio-Rad). Plasmid p1.3HBcl was prepared at 10 -fold dilutions $\left(2 * 10^{4}-2 * 10^{9}\right.$ copies $\left./ \mathrm{ml}\right)$ to generate a standard curve in parallel PCR reactions.

\section{Animals}

Eleven 8-week-old female FRG $\left(\mathrm{Fah}^{-/-} / \mathrm{Rag}^{-/-} / \mathrm{IL}-2 \mathrm{Rg}^{\prime}\right.$ $\left.{ }^{-}\right)$mice were housed at room temperature with controlled humidity and on a $12 \mathrm{~h} / 12 \mathrm{~h}$ light/dark cycle (lights on at 7.00 a.m.) at the Animal Center of the Academia Sinica, Taipei, Taiwan. The weight reached to $25 \mathrm{~g}$ in average at 8 weeks old. The food applied was Picolab Rodent Diet 20 (Lab Supply, Inc). Mice were housed in groups using high quality wood pellet hygienic litter bedding (Lignocel HBK 1500-3000, Rettenmaier \& Sönne, Germany). Epigallocatechin gallate (EGCE) was injected through the tail vein. Blood was taken from the inferior vena cava during deep anesthesis. The use of animals for this research was approved by the Animal Research Committee of the Academia Sinica and all procedures followed The Guide for the Care and Use of Laboratory Animals (NIH publication, 85-23, revised 1996) and the guidelines of the Animal Welfare Act, Taiwan. On the day of sacrifice, a laparotomy was performed under ketamine and xylazine anesthesia (intramuscular injection of $100 \mathrm{mg} / \mathrm{kg}$ body mass and $5 \mathrm{mg} /$ $\mathrm{kg}$ body mass, respectively), and whole-blood samples were collected via cardiac puncture.

Generation of human liver chimeric (Hu-FRG) mice

To generate human liver chimeric (Hu-FRG) mice, cryo-preserved human hepatocytes were purchased from 
BD Biosciences (San Jose, CA, USA) and CellzDirect/Invitrogen (Durham, NC, USA). FRG $\left(\mathrm{Fah}^{-/-} / \mathrm{Rag}^{-/-} /\right.$ IL-2R $\gamma^{\prime-}$ ) mice were transplanted as described previously, except for adopting a protocol of gradually decreasing NTBC in the drinking water [19]. One million viable hepatocytes in $200 \mu \mathrm{l}$ of William's E medium (Invitrogen Life Technologies, Carlsbad, CA, USA) were injected intrasplenically via a 27 -gauge needle. The transplanted mice were given plain water after surgery. To monitor the transplantation rate of human hepatocytes, small amounts of blood were collected monthly from the tail veins of $\mathrm{Hu}-\mathrm{FRG}$ mice and the serum human albumin (hAlb) levels were determined using a Human Albumin ELISA Quantitation Set (Bethyl Laboratories, Montgomery, TX, USA) according to the manufacturer's protocol. It takes about 4 months to reach human serum albumin concentration of $\geqq 1 \mathrm{mg} / \mathrm{mL}$. Total eleven mice were transplanted and six Hu-FRG mice with human serum albumin concentrations of $\geqq 1 \mathrm{mg} / \mathrm{mL}$ were selected for use in the HBV infection studies.

\section{HBV infection of Hu-FRG mice}

The Hu-FRG mice were subsequently divided randomly into two groups (HBV, $n=3$, and $\mathrm{HBV}+$ EGCG, $n=3)$. (-)-Eepigallocatechin-3-gallate (EGCG) ( $\geq 97.0 \%$, HPLC grade) was purchased from Sigma-Aldrich. An inoculum of $5^{*} 10^{7}$ copies of $\mathrm{HBV}$ was injected intraperitoneally on day 1 . The mice were injected intravenously with EGCG diluted in sterile saline at a concentration of $10 \mathrm{mg} / \mathrm{mL}(50 \mu \mathrm{L} / 10 \mathrm{~g}$ body weight). Injections (50 mg/kg) of EGCG were given twice a day on days 1 to 5 (Fig. 3).

Serological analysis and tissue characterization of Hu-FRG liver chimerism

After HBV infection, mice were sacrificed at week 4 for serological and intrahepatic analyses. Liver specimens were removed during sacrifice and were snap-frozen in liquid nitrogen for further histological and molecular analyses. Serum HBV DNA was quantified by realtimeqPCR at weeks 2 and 4. Serum HBsAg levels were determined by ELISA Quantitation Set (Bio-Rad Laboratories) according to the manufacturer's protocol. To stain human hepatocytes, cryostat sections of chimeric mouse livers were immunostained with human Fah antibodies (Cell Signaling) and polyclonal rabbit anti-HBcAg (Abcam) to detect HBV core antigen (HBcAg). Briefly, the liver sections were incubated with Fah and $\mathrm{HBcAg}$ antibodies at $4{ }^{\circ} \mathrm{C}$ overnight, then followed by Alexa488conjugated goat IgG and Alexa594-conjugated goat IgG at $37{ }^{\circ} \mathrm{C}$ for $1 \mathrm{~h}$. Hoechst 33258 (Sigma-Aldrich) was used along with the secondary antibody to detect nucleus. The immunostained samples were detected by Leica DM6000B microscope.

\section{Statistical analysis}

All values are expressed as mean $\pm \mathrm{SE}$. Each value is the mean of at least three animals in each group in vivo experiments. Student's t-test was used for statistical comparison. * indicates that the values are significantly different from the control ( ${ }^{*}, p<0.05 ;{ }^{* *}, P<0.01{ }^{* * * *}, P \leq 0.001$.).

\section{Results}

\section{Inhibitory effect of EGCG on HBV infection}

To evaluate the effects of EGCG on HBV infectivity and replication, $\mathrm{HuS}-\mathrm{E} / 2$ cells were infected with $\mathrm{HBV}$ derived from HepG2.2.15 cells in the presence of EGCG. The replication efficiency was determined by measuring rcDNA and RNA by PCR and RT-PCR, respectively. EGCG treatment during infection resulted in a dose-dependent decrease of HBV rcDNA (Fig. 1a) and HBsAg mRNA (Fig. 1b) in $\mathrm{HuS}-\mathrm{E} / 2$ cells. In addition, when the cells were treated with $10 \mu \mathrm{M}$ EGCG, HBV mRNA levels were reduced by $80 \%$ compared to control cells. The half-maximal inhibitory concentration $\left(\mathrm{IC}_{50}\right)$ was estimated to be below $10 \mu \mathrm{M}$. Taken together, these results suggest that HBV infection is inhibited by EGCG treatment.

\section{EGCG inhibited HBV infection in the Hu-FRG mouse model}

To evaluate the EGCG-associated inhibition of HBV infection in vivo, we generated human liver chimeric

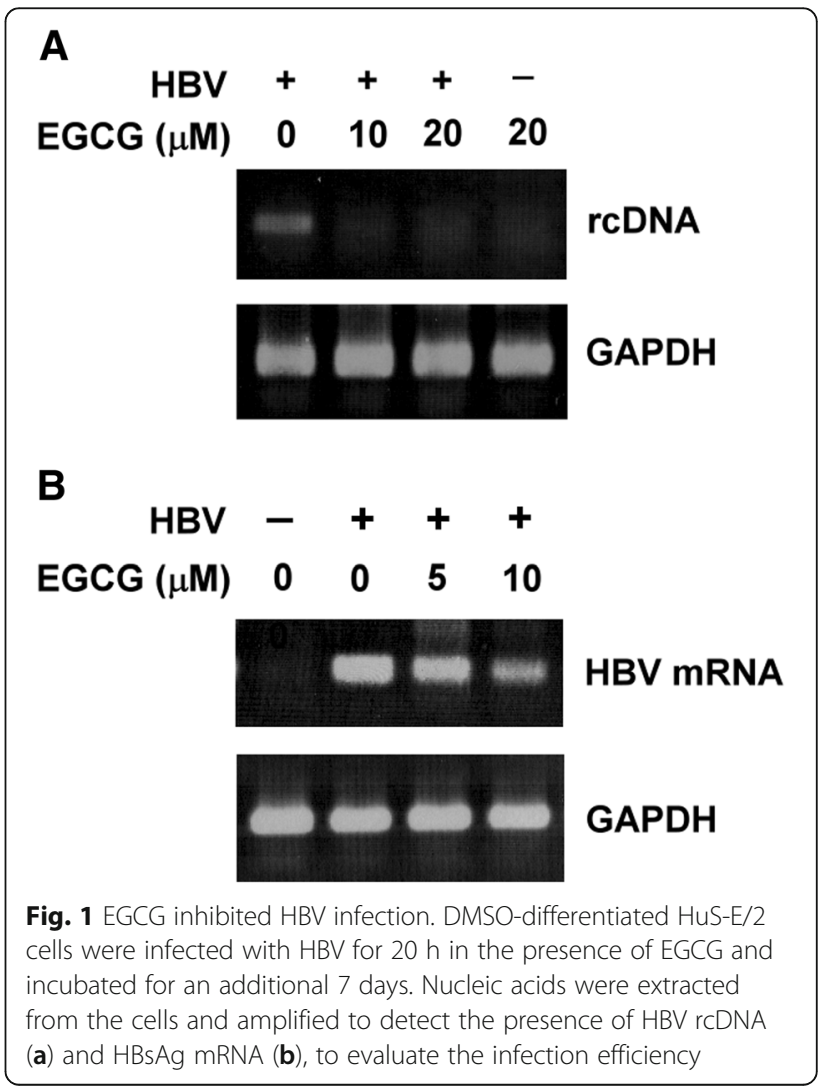




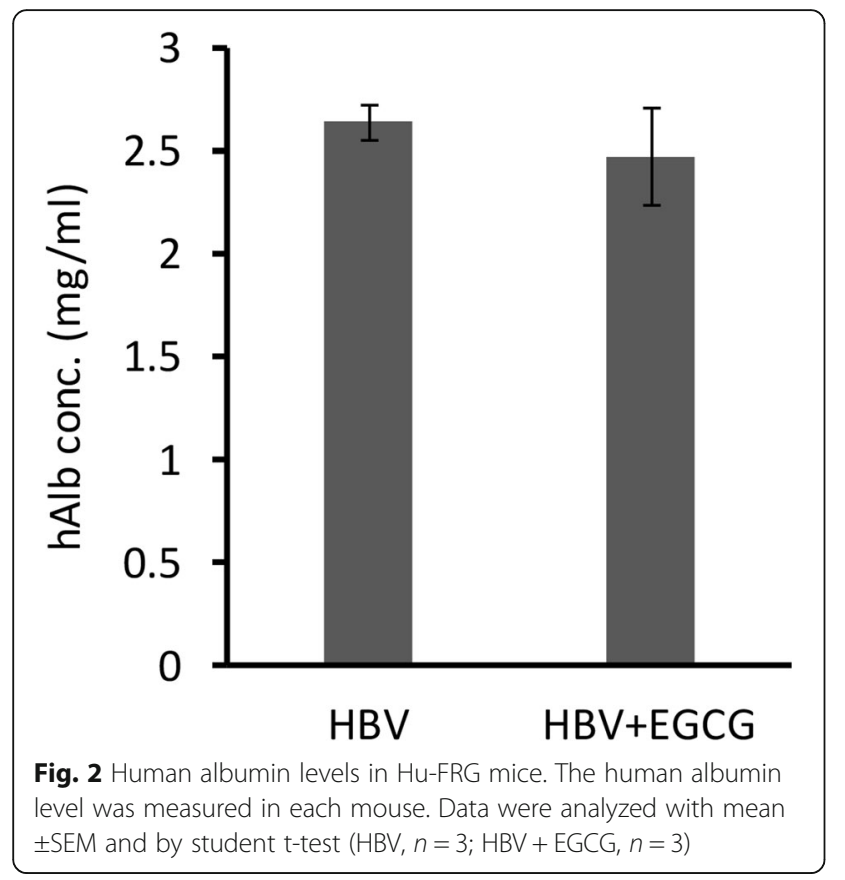

(Hu-FRG) mice. We measured the human serum albumin (hAlb) concentrations in the Hu-FRG mice and selected mice with $\geqq 1 \mathrm{mg} / \mathrm{mL}$ hAlb for the HBV infection studies (Fig. 2). The scheme of EGCG treatment and Hu-FRG mice challenge schedule was shown in Fig. 3. Realtime-qPCR and ELISA assay were used to detect HBV DNA and HBsAg, respectively, in mice serum. Compared to the control group, the HBV DNA copy number was significantly lower $(p \leq 0.05)$ after 4 weeks of treatment with EGCG and challenge with HBV (Fig. 4a). A marked reduction $(p \leq 0.01)$ in HBsAg protein level by $70 \%$ was detected (Fig. $4 \mathrm{~b}$ ). These data suggest clearly that EGCG inhibits HBV infection in human liver chimeric mice.

EGCG inhibited expression of fah and $\mathrm{HBCAg}$ in the livers of human chimeric mice

Liver tissue from Hu-FRG chimeric mice was examined to detect HBV infection with/without EGCG treatment. The human Fah-expressing cells were successfully implanted in the mouse livers (Fig. 5) and the HBV infection was monitored by detecting hepatitis B core antigen ( $\mathrm{HBcAg}$ ) expression. We found that, when the mice were treated with EGCG, the levels of expression of HBcAg in the human cells were lower than in the mice without EGCG treatment. Therefore, based on the immunostaining of the liver tissue of the chimeric mice, we confirmed the inhibitory effect of EGCG on HBV infection.

\section{Discussion}

The major components of green tea, polyphenols, which are also known as catechins, have been shown to have a therapeutic effect on a myriad of diseases [22-24]. The catechins in green tea include epicatechin (ECG), epigallocatechin (EGC), epicatechin (EC), catechin (C) and epigallocatechin gallate (EGCG) and EGCG is

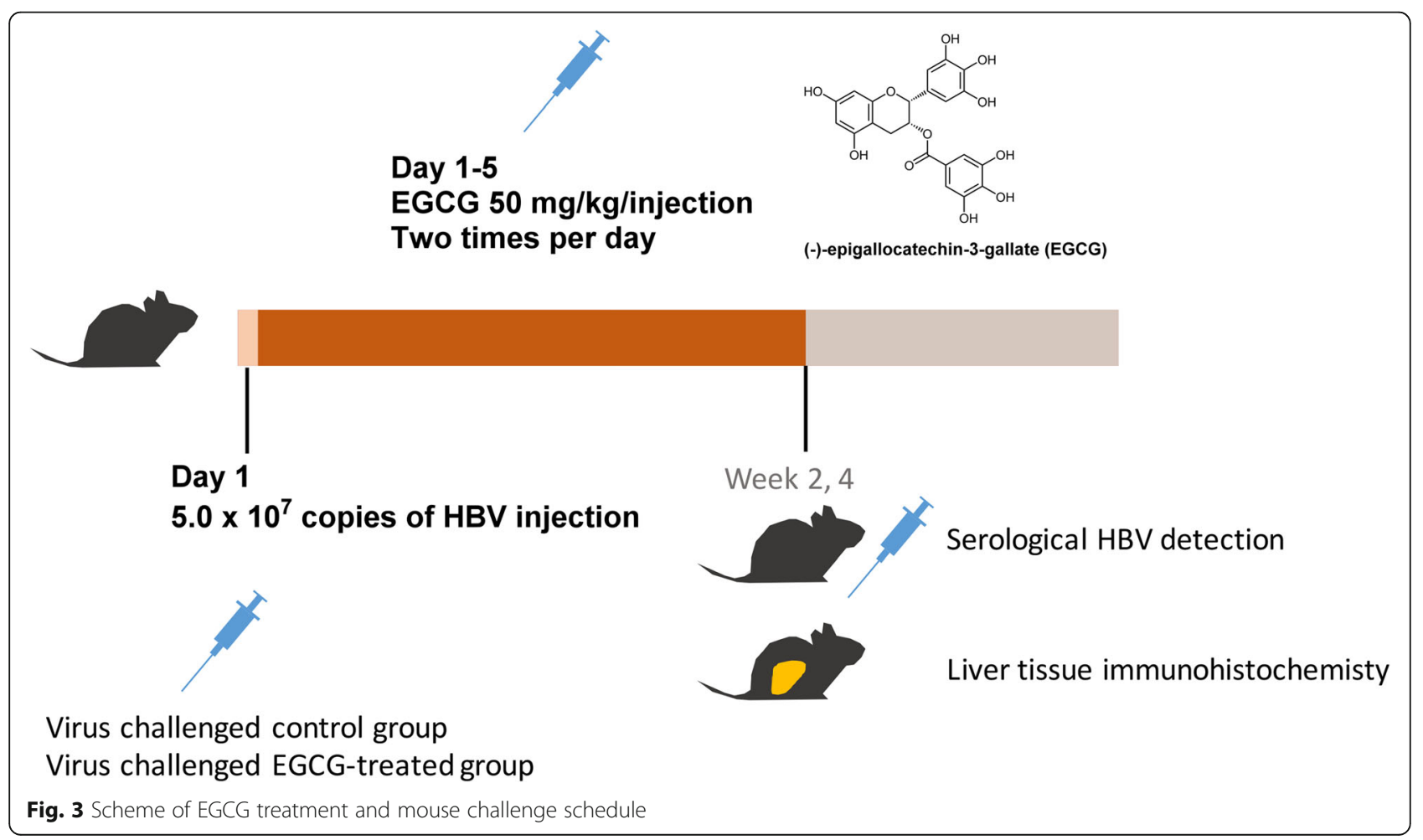



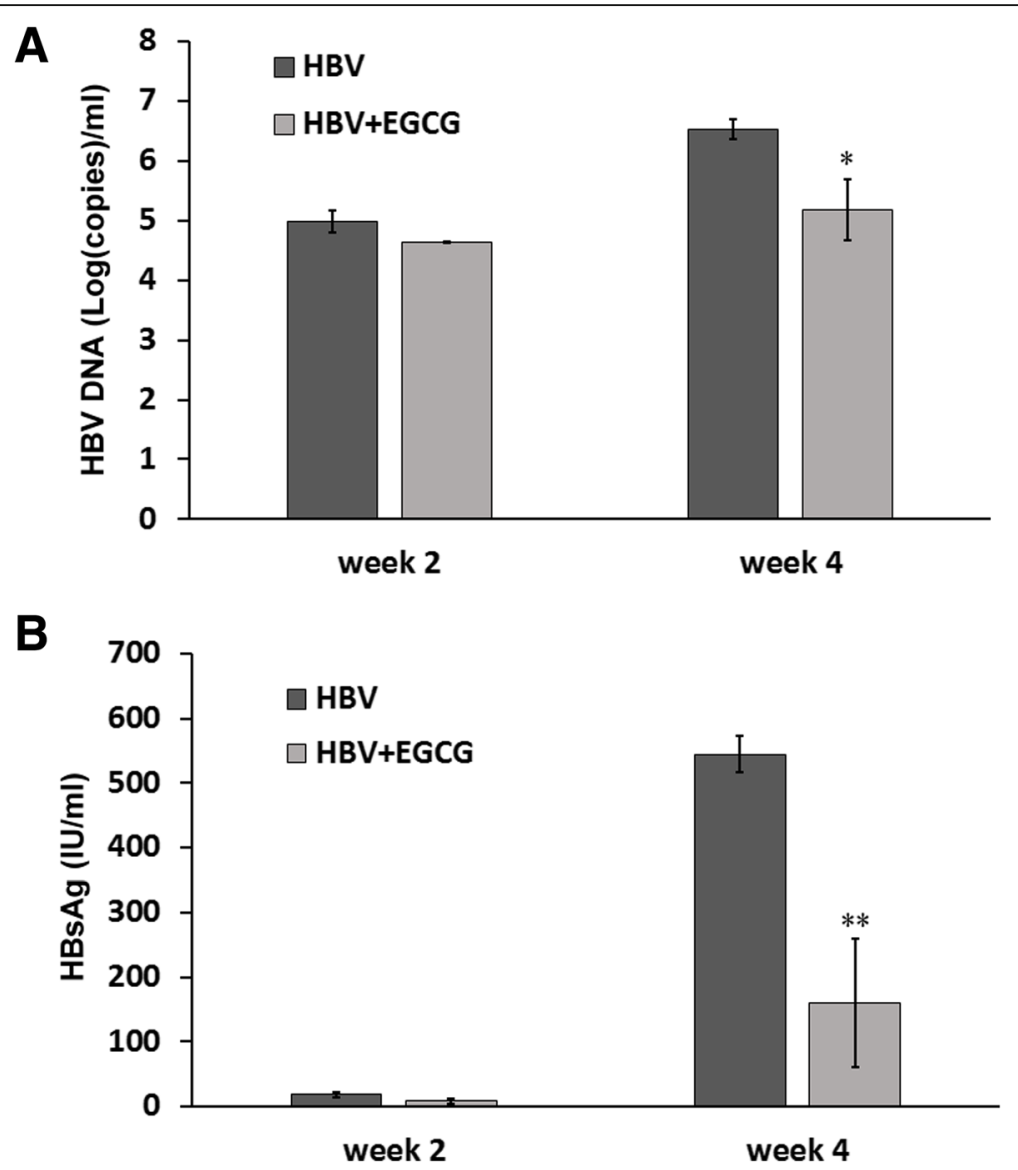

Fig. $4 \mathrm{HBV}$ titers in Hu-FRG mice. HBV titers were determined as HBV DNA copies (a), and HBV HBsAg expression levels (b). The data are expressed with mean \pm SEM and were analyzed by student t-test (HBV, $\mathrm{n}=3$; HBV+EGCG, $\mathrm{n}=3$; ${ }^{*} p<0.05$, ${ }^{* *} p<0.01$ ).

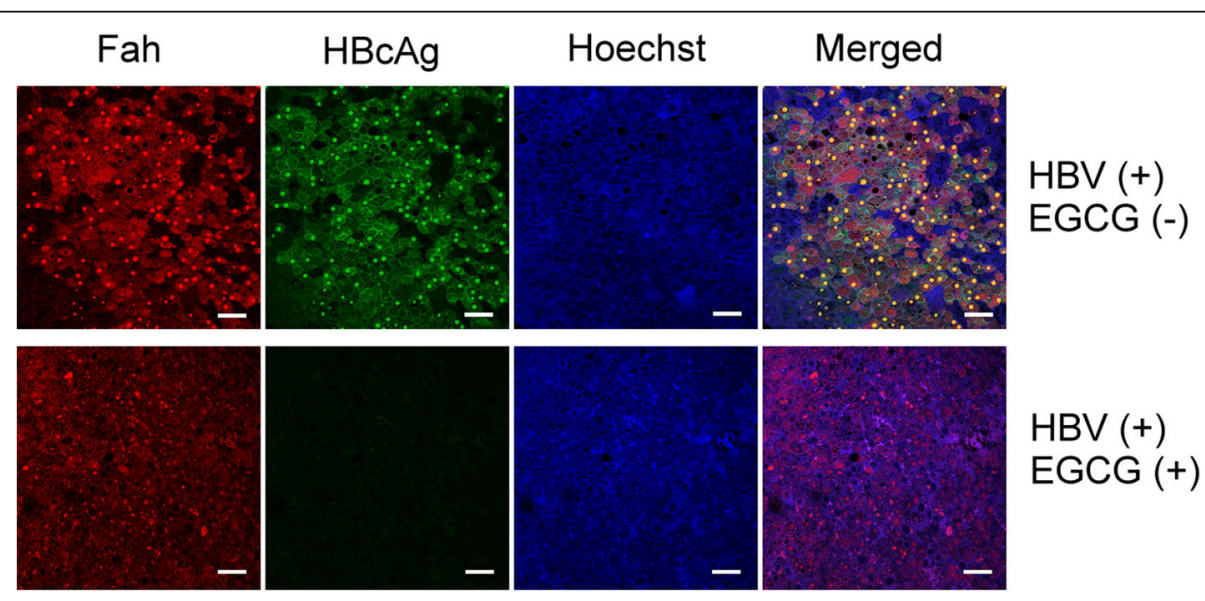

Fig. 5 Expression of Fah and HBCAg in the livers of human chimeric mice. Expression of Fah and HBcAg were examined by immunofluorescence staining with antibodies against Fah and HBCAg, followed by confocal microscopy. The bars on the images represent $100 \mu \mathrm{m}$ 
considered to be the most important in terms of its anti-viral effects through various mechanisms [14, 25]. A previous study by our team showed that EGCG induced clathrin-dependent endocytosis of NTCP and inhibited HBV entry in vitro [17]. In addition, EGCG has been shown to be an inhibitor of the viral serine protease involved in HCV entry [26]. The mechanism of inhibition by EGCG of cellular entry by herpes simplex virus (HSV) may be through disruption of the viral envelope [27]. Several pathways have been reported for the EGCG inhibitory effect on Epstein-Barr virus (EBV) infection, such as interference with the AP-1 pathway [28], reduction of the ability of the virus to bind to host DNA [29], degradation of viral RNA and down-regulation of viral lytic-associated signaling [30].

However, the methods used to elucidate the effects of EGCG were based on cultured cells, including primary human hepatocytes [31]. Therefore, after we confirmed and optimized the EGCG inhibitory efficiency in HuS-E/ 2 cells, we used a chimeric mouse model to investigate the effect of EGCG on HBV infection in vivo. Previously, an immunodeficient model, based on the urokinase-type plasminogen activator (uPA) mouse, was used for HBV and HCV research [32-34]. To solve the limitation of the uPA mouse model that had high mortality and was difficult to manipulate, the FRG-chimeric mouse model was developed [20]. In our study, we first generated Hu-FRG mice whose livers were repopulated with human hepatocytes. We showed the implantation was efficient by measuring the human albumin level, with no significant difference between the two groups (Fig. 2). Furthermore, we designed an HBV infection strategy and successfully challenged $\mathrm{Hu}-\mathrm{FRG}$ mice with HBV during EGCG treatment (Fig. 3). Measurement of the HBV DNA copy number and HBsAg titer, as well as immunohistochemical analysis of the liver tissue, provided the solid evidence of inhibition of HBV infection by EGCG (Figs. 4 and 5).

Generally, the HBV DNA copy number exceeded $1.0 \times 10^{7}$ copies $/ \mathrm{ml} 4$ weeks after viral challenge in the control group, accompanied by a high titer of HBsAg. We compared the HBV DNA copy number and HBsAg concentration between the untreated and EGCG-treated groups of mice and saw little difference after 2 weeks but, critically, 4 weeks after infection, the HBV titers in the EGCG-treated mice were over 100 fold lower than the control group. To explain the time lag before viral inhibition was apparent, we hypothesized that either the increasing dosage or injection frequency of EGCG blocks HBV entry. We found, despite that the half-life of EGCG is approximately less than $1 \mathrm{~h}$ [35], the strategy we applied to boost EGCG was effective and stable enough to block HBV infection. The increasing dosage of EGCG would maintain the EGCG concentration in blood and overcome the degradation of EGCG due to its half-life, which make apparent the effect of EGCG in inhibiting HBV entry into the hepatocytes. Therefore, we may increase the dosage of EGCG in future experiments.

\section{Conclusions}

In the present study, the inhibitory effect of EGCG on HBV infection and replication was demonstrated in vitro. Further, it is clear that the use of the Hu-FRG chimeric mouse model to evaluate the inhibitory effect of EGCG was robust and EGCG may have therapeutic potential for the treatment of $\mathrm{HBV}$-associated liver diseases.

\section{Abbreviations \\ EGCG: Epigallocatechin gallate; Fah: Fumacrylacetoacetate; FRG mice: Fah ${ }^{-/}$/ Rag2 $2^{-1-} /$ IL-2RY'- mice; hAlb: Human albumin; HBCAg: HBV core antigen; HBsAg: Hepatitis B surface antigen; HBV: Hepatitis B virus; NTCP: Sodium taurocholate cotransporting polypeptide}

\section{Acknowledgments}

We thank Dr. K. Shimotohno (Kyoto University, Japan) for providing HuS-E/2 cells, and Dr. Mi-Hua Tao (Academia Sinica, Taiwan) for providing human liver chimeric mice.

\section{Funding}

This work was supported by research grant MOST 104-2320-B-077-003- and MOST 106-2320-B-010-038- from the Ministry of Science and Technology, Taiwan.

\section{Availability of data and materials}

The datasets used and/or analysed during the current study available from the corresponding author on reasonable request.

\section{Authors' contributions}

$\mathrm{YHL}, \mathrm{CPS}$, and $\mathrm{HCH}$ carried out the experiments. JCC and HKL analyzed the data. $\mathrm{CH}$ wrote the paper. All authors read and approved the final manuscript.

\section{Ethics approval and consent to participate}

All animal experiments, including mouse manipulations (e.g. dosing and bleeding), were performed under a protocol (ASIACUC permit number 14-01-637) approved by Academia Sinica Institutional Animal Care and Usage Committee (Taipei, Taiwan).

\section{Consent for publication}

Not applicable.

\section{Competing interests}

The authors declare that they have no competing interest.

\section{Publisher's Note}

Springer Nature remains neutral with regard to jurisdictional claims in published maps and institutional affiliations.

\footnotetext{
Author details

${ }^{1}$ Department of Chemistry, Chinese Culture University, Taipei 11114, Taiwan. ${ }^{2}$ Institute of Biomedical Sciences, Academia Sinica, Taipei 11529, Taiwan.

${ }^{3}$ Department of Applied Science, National Tsing Hua University South Campus, Hsinchu 30014, Taiwan. ${ }^{4}$ Department of Biochemical Science and Technology, National Chiayi University, Chiayi 60004, Taiwan. ${ }^{5}$ National Research Institute of Chinese Medicine, Ministry of Health and Welfare, Taipei 11221, Taiwan. ${ }^{6}$ Program in Clinical Drug Development of Chinese Herbal Medicine, Taipei Medical University, Taipei 11001, Taiwan. ${ }^{7}$ Department of Biotechnology and Laboratory Science in Medicine, National Yang-Ming
} 
University, No. 155, Sec. 2, Linong St., Beitou District, Taipei 11221, Taiwan. ${ }^{8}$ Department of Earth and Life Sciences, University of Taipei, Taipei 11153, Taiwan.

Received: 16 July 2018 Accepted: 28 August 2018

Published online: 06 September 2018

\section{References}

1. Arbuthnot P, Kew M. Hepatitis B virus and hepatocellular carcinoma. Int J Exp Pathol. 2001;82(2):77-100.

2. Beasley RP. Hepatitis B virus. The major etiology of hepatocellular carcinoma. Cancer. 1988;61(10):1942-56

3. Yang JG, et al. Epigallocatechin-3-gallate affects the growth of LNCaP cells via membrane fluidity and distribution of cellular zinc. J Zhejiang Univ Sci B. 2009:10(6):411-21.

4. Chen WN, Oon CJ. Human hepatitis B virus mutants: significance of molecular changes. FEBS Lett. 1999;453(3):237-42.

5. Mehta A, et al. Hepatitis B virus (HBV) envelope glycoproteins vary drastically in their sensitivity to glycan processing: evidence that alteration of a single N-linked glycosylation site can regulate HBV secretion. Proc Natl Acad Sci U S A. 1997;94(5):1822-7.

6. $\mathrm{Ni}$ Y, et al. The pre-s2 domain of the hepatitis $\mathrm{B}$ virus is dispensable for infectivity but serves a spacer function for L-protein-connected virus assembly. J Virol. 2010;84(8):3879-88.

7. Cooper A, Paran N, Shaul Y. The earliest steps in hepatitis B virus infection. Biochim Biophys Acta. 2003:1614(1):89-96.

8. De Meyer S, et al. Organ and species specificity of hepatitis B virus (HBV) infection: a review of literature with a special reference to preferential attachment of HBV to human hepatocytes. J Viral Hepat. 1997;4(3):145-53.

9. $\quad \mathrm{Yan} \mathrm{H}$, et al. Sodium taurocholate cotransporting polypeptide is a functional receptor for human hepatitis B and D virus. Elife. 2012;1:e00049.

10. Watashi $\mathrm{K}$, et al. NTCP and beyond: opening the door to unveil hepatitis $B$ virus entry. Int J Mol Sci. 2014;15(2):2892-905.

11. Yan $\mathrm{H}$, et al. Molecular determinants of hepatitis B and D virus entry restriction in mouse sodium taurocholate cotransporting polypeptide. J Virol. 2013:87(14):7977-91.

12. Gripon P, et al. Infection of a human hepatoma cell line by hepatitis B virus. Proc Natl Acad Sci U S A. 2002;99(24):15655-60.

13. Huang $\mathrm{HC}$, et al. Entry of hepatitis B virus into immortalized human primary hepatocytes by clathrin-dependent endocytosis. J Virol. 2012;86(17):9443-53.

14. Song JM, Lee KH, Seong BL. Antiviral effect of catechins in green tea on influenza virus. Antivir Res. 2005;68(2):66-74.

15. Calland $\mathrm{N}$, et al. (-)-Epigallocatechin-3-gallate is a new inhibitor of hepatitis C virus entry. Hepatology. 2012;55(3):720-9.

16. Isaacs CE, et al. Epigallocatechin gallate inactivates clinical isolates of herpes simplex virus. Antimicrob Agents Chemother. 2008:52(3):962-70.

17. Huang $\mathrm{HC}$, et al. Epigallocatechin-3-gallate inhibits entry of hepatitis $B$ virus into hepatocytes. Antivir Res. 2014;111:100-11.

18. Grompe M, al-Dhalimy M. Mutations of the fumarylacetoacetate hydrolase gene in four patients with tyrosinemia, type I. Hum Mutat. 1993;2(2):85-93.

19. Bissig KD, et al. Repopulation of adult and neonatal mice with human hepatocytes: a chimeric animal model. Proc Natl Acad Sci U S A. 2007; 104(51):20507-11.

20. Azuma $\mathrm{H}$, et al. Robust expansion of human hepatocytes in fah-/-/Rag2 -/-/I2rg-/- mice. Nat Biotechnol. 2007;25(8):903-10.

21. Aly $\mathrm{HH}$, et al. Serum-derived hepatitis $\mathrm{C}$ virus infectivity in interferon regulatory factor-7-suppressed human primary hepatocytes. J Hepatol. 2007; 46(1):26-36

22. Mak JC. Potential role of green tea catechins in various disease therapies: progress and promise. Clin Exp Pharmacol Physiol. 2012;39(3):265-73.

23. Chen XQ, et al. Preventive effects of Catechins on cardiovascular disease. Molecules. 2016;21(12)

24. Shirakami Y, et al. Catechins and its role in chronic diseases. Adv Exp Med Biol. 2016:929:67-90.

25. Ide K, et al. Anti-influenza virus effects of Catechins: a molecular and clinical review. Curr Med Chem. 2016:23(42):4773-83.

26. Zuo G, et al. Activity of compounds from Chinese herbal medicine Rhodiola kirilowii (regel) maxim against HCV NS3 serine protease. Antivir Res. 2007: 76(1):86-92.

27. Isaacs $C E$, et al. Digallate dimers of (-)-epigallocatechin gallate inactivate herpes simplex virus. Antimicrob Agents Chemother. 2011;55(12):5646-53.
28. Zhao Y, et al. Epigallocatechin-3-gallate interferes with EBV-encoding AP-1 signal transduction pathway. Zhonghua Zhong Liu Za Zhi. 2004;26(7):393-7.

29. Chen YL, Tsai HL, Peng CW. EGCG debilitates the persistence of EBV latency by reducing the DNA binding potency of nuclear antigen 1. Biochem Biophys Res Commun. 2012;417(3):1093-9.

30. Liu S, et al. (-)-Epigallocatechin-3-gallate inhibition of Epstein-Barr virus spontaneous lytic infection involves ERK1/2 and PI3-K/Akt signaling in EBVpositive cells. Carcinogenesis. 2013;34(3):627-37.

31. Verrier ER, Schuster C, Baumert TF. Advancing hepatitis B virus entry inhibitors. J Hepatol. 2017;66(4):677-9.

32. Heckel JL, et al. Neonatal bleeding in transgenic mice expressing urokinasetype plasminogen activator. Cell. 1990;62(3):447-56.

33. Dandri $\mathrm{M}$, et al. Repopulation of mouse liver with human hepatocytes and in vivo infection with hepatitis B virus. Hepatology. 2001;33(4):981-8.

34. Mercer DF, et al. Hepatitis $C$ virus replication in mice with chimeric human livers. Nat Med. 2001;7(8):927-33.

35. Xifro $X$, et al. Novel epigallocatechin-3-gallate (EGCG) derivative as a new therapeutic strategy for reducing neuropathic pain after chronic constriction nerve injury in mice. PLoS One. 2015;10(4):e0123122.

\section{Ready to submit your research? Choose BMC and benefit from:}

- fast, convenient online submission

- thorough peer review by experienced researchers in your field

- rapid publication on acceptance

- support for research data, including large and complex data types

- gold Open Access which fosters wider collaboration and increased citations

- maximum visibility for your research: over 100M website views per year

At $\mathrm{BMC}$, research is always in progress.

Learn more biomedcentral.com/submissions 